\title{
Intelecto y prudencia De la episteme a la política en la teoría de Christine de Pizan
}

\section{( Juliana Eva Rodriguez}

Instituto Multidisciplinario de Historia y Ciencias Humanas / CONICET, Argentina.

ORCID: 0000-0002-1341-4398

Recibido: 19 de febrero de 2021, aceptado: 21 de abril de 2021

\begin{abstract}
Resumen
Christine de Pizan da vida a su gobernante ideal a partir de la tradición medieval del aristotelismo político y su noción de lo "arquitectónico". Construido a modo de una arquitectura viviente de ciencias, el rey sabio aparece dominando la paleta de saberes, que va desde la episteme hasta los conocimientos más prácticos. Teoría y práctica se encuentran, así, en la base de su construcción de lo político. Pero ¿en qué medida la autora se consagra a brindar una explicación del pasaje de las ciencias, sobre todo, aquel que va de las especulativas al registro práctico de la ciencia política? Si el rey se distingue por ser un sabio al tiempo que un experto en las diversas ciencias (filosofíateología, astrología, gramática, dialéctica, retórica, música, geometría, astronomía, aritmética y arquitectura), cabe preguntarse si acaso la autora teoriza sobre dicho pasaje de lo teórico a lo práctico que constituye la esencia de su pensamiento. ¿Cuál es el canal para volcar la episteme al servicio del Estado? Al respecto, sostengo la hipótesis de que tanto la prudencia como el entendimiento o intelecto parecen ser los dos componentes de la sabiduría perfecta que la escritora aúna en una perfecta díada; operación, esta, que le permite explicar el pasaje de todas las ciencias al plano de lo contingente. ¿Acaso no es, gracias a esta operación, que el rey sabio de Christine de Pizan aparece como el intelecto supremo de la comunidad política, encarnada en el reino de Francia? ¿No son las ciencias, de este modo, redituables en servicio del Estado?
\end{abstract}

PALABRAS CLAVES: ARQUITECTURA DE CIENCIAS, INTELECTO, MONARQUÍA FRANCESA, PRUDENCIA, SABIDURÍA REGIA. 


\title{
Intellect and prudence
}

From episteme to politics in the theory of Christine de Pizan

\begin{abstract}
Christine de Pizan gives life to her "ideal ruler" based on the political Aristotelianism and its notion of the "architectonic". Built as a living architecture of sciences, the wise king appears dominating the range of different knowledges ranging from the episteme to the practical knowledge. Theory and practice are thus at the basis of her construction of the political matter. But to what extent does the author devote herself to providing an explanation of the transfer of science, especially the speculative science to the practical record of political science? In other words, whether the king is distinguished by being a sage at the same time as an expert in the various sciences (philosophy-theology, astrology, grammar, dialectics, rhetoric, music, geometry, astronomy, arithmetic, and architecture), it is necessary to ask whether the author theorizes about this transfer from the theoretical to the practical that constitutes the essence of her thought. What is the medium for translating the episteme into the service of the State? In this regard, I argue that both prudence and understanding (intellect) seem to be the two components of the perfect wisdom that the writer combines into a perfect dyad; operation, which allows her to explain the transfer from all sciences to the political arena. Isn't it thanks to this operation that the wise king of Christine de Pizan appears as the supreme intellect of the political community, embodied in the kingdom of France? Are not the sciences thus profitable in the service of the State?
\end{abstract}

KEYWORDS: ARCHITECTURE OF SCIENCES, FRENCH MONARCHY, INTELLECT, PRUDENCE, ROYAL WISDOM.

\section{Introducción}

En su Livre des fais et bonnes meurs du sage roy Charles $V$, escrito en 1404 por encargo del duque Felipe de Borgoña, Christine de Pizan expone su teoría del gobernante ideal a partir de la figura de Carlos V, rey de su infancia y adolescencia. ${ }^{1}$ Allí, la escritora da vida a un rey sabio, construido sobre la base del aristotelismo político, ${ }^{2}$ quien se presenta como una arquitectura de ciencias; una especie de taxonomía viviente de saberes desplegados a través de una ingente cantidad de exempla. Es precisamente en el libro III, consagrado a la sabiduría, donde el conjunto de saberes poseídos por el rey adquiere un significado en el registro práctico (mundo contingente) donde se ejerce la función real.

En principio, el libro III se abre con una definición extensa de sabiduría, extraída del libro VI de la Ética a Nicómaco: "decimos que arte, prudencia, entendimiento (intelecto), ciencia y sabiduría son los componentes de la perfecta sabiduría" (Livre des fais, III.2). ${ }^{3}$ En el pensamiento de Christine, las virtudes intelectuales se reúnen en la perfecta sabiduría, la cual aparece como una mega virtud que agrupa todos los saberes y virtudes poseídos por el rey sabio. Luego, cada uno de ellos ocupa un lugar jerárquico según sus respectivos objetos. Así, en buena aristotélica, Christine concluye que, entre todas las ciencias y artes, las especulativas se encuentran por encima de las prácticas, y que "sapience" (teología), en tanto considera las causas y principios primeros, es aquella de mayor sabiduría (cf. ibid.). No obstante, por fuera de estas definiciones introductorias, los distintos argumentos se vuelven operativos

\footnotetext{
1 Véase Le Ninan, 2013; Rodriguez, 2015.

2 Por aristotelismo político hacemos referencia a la corriente filosófica constituida por escritores medievales que aplican en sus textos el pensamiento aristotélico de la Ética y la Política traducidas al latín en el curso del siglo XIII. Entre ellos podemos citar, primordialmente, a Tomás de Aquino, Egidio Romano y Nicolás Oresme. Véase Quillet, 1984.

3 Christine de Pizan, Livre des fais, III.2: 198: “dirons que art, prudence, entendement, science et sapience sont les suppoz de perfaitte sagece". Todas las traducciones son propias, salvo expresa indicación en contrario.
} 
en el terreno de la demostración. El apodo de "Carlos el Sabio" aparece entonces como el derivado del "efecto de sabiduría" que se manifiesta y afirma en cada una de las "obras" del monarca (cf. Livre des fais, III. Prol.: 197). De ahí, el sentido del libro III anunciado claramente en su prólogo: "Se proceda, entonces, a la alabanza de vuestras valiosas obras" (ibid.). ${ }^{4}$

Pero ¿en qué medida la autora se consagra a brindar una explicación del pasaje de las ciencias, sobre todo, aquel que va de las especulativas al registro de lo práctico? En otras palabras, si el rey se distingue por ser un sabio al tiempo que un experto en las diversas ciencias (filosofía-teología, astrología, gramática, dialéctica, retórica, música, geometría, astronomía, aritmética y arquitectura), cabe preguntarse si acaso la autora teoriza sobre dicho pasaje, de lo teórico a lo práctico, que constituye la esencia de su pensamiento. Al respecto, sostengo la hipótesis de que tanto la prudencia como el entendimiento (intelecto) parecen ser los dos componentes de la sabiduría perfecta que la escritora aúna en una perfecta díada; movimiento, este, que permite entender el pasaje de todas las ciencias al terreno de la práctica (plano de lo contingente).

\section{El Entendimiento}

\subsection{La virtud del entendimiento: fundamento de la "perfecta sabiduría"}

Siguiendo el libro VI de la Ética a Nicómaco, Christine define el entendimiento como el campo de demostración de los primeros principios, mientras que la ciencia es aquel de las demostraciones por las causas inferiores: "el campo del intelecto es aquel de los primeros principios" (Livre desfais, III.2). ${ }^{5}$ Desde esta perspectiva, el entendimiento o intelecto se presenta como una disposición que permite adquirir las ciencias a objeto de alcanzar la ciencia suprema ("sapience"): la metafísica (filosofía) o ciencia divina (teología). Por de pronto, podemos apreciar la peculiaridad de esta definición, en tanto y en cuanto el entendimiento -dentro de la perfecta sabiduría- aparece en su capacidad más elevada: aquella de alcanzar los primeros principios.

Por otra parte, más allá de esta definición principal, la autora recurre al concepto de entendimiento en varias oportunidades a lo largo de su obra. De este modo, Christine, quien dice basarse en las premisas del Secretum Secretorum -para la época medieval, obra aristotélica-, formula la idea del intelecto como soberano del cuerpo humano. Así, del mismo modo en que el rey impera en la ciudad, el entendimiento o intelecto impera en el conjunto del cuerpo humano. Por consiguiente, si el hombre aparece como la más perfecta criatura sobre la tierra, la causa está en su intelecto, el cual lo acerca al conocimiento divino. Tal idea es plasmada al comienzo del libro primero del Livre desfais, cuando al describir la Creación, la autora se refiere al hombre:

comme l'omme en soy, au regart des basses substances, soit chose moult perfaitte; car, si comme Aristote dit, ou livre des secrez, quant le tres hault, c'est Dieu le glorieux, eut proposé faire homme, pour ce qu'il fust à sciences dispost, son corps constitua ainsi comme une cité, et l'entendement il establi Roy et l'assist ou souverain lieu de lui, etc. (Livre des fais, I.12: 54).

respecto de las materias groseras, el hombre es una cosa muy perfeccionada; por cuanto Aristóteles dice en su Libro de los secretos, cuando el Muy-Elevado, es decir, Dios en Majestad, quiso crear al hombre apto para el conocimiento de las ciencias, concibió su cuerpo como una ciudad y al intelecto como su Rey: es por esto que lo ubicó en el lugar más soberano (Livre des fais, I.12).

4 Ibid., III. Prol.: 197: "Soit doncques procedé à la louenge de sapience et de voz valeureuses euvres". 
Pero si el entendimiento es lo que diferencia al hombre de las bestias y lo eleva al rango de criatura superior, Christine parece ser reacia a extender la posesión de entendimiento -aquella disposición para el estudio de la metafísica- a todos los hombres por igual, al menos esta es la postura sostenida en el Livre des fais. Ciertamente, en su Advision Cristine (1405), la autora comenta sobre la diversidad de entendimientos que van desde los más elementales a los más sutiles.

De acuerdo con "la disposición de los entendimientos" las obras humanas se dividen en buenas o malas, groseras o sutiles. ${ }^{6}$ Sin embargo, más allá de esta referencia de carácter universalista ("todos los hombres desean, por naturaleza, saber"), el criterio del entendimiento (incluso en la Advision) parece estar restringido a aquella inteligencia que permite al hombre pasar por todas las ciencias hasta llegar a la ciencia soberana -la metafísica-y que se restringe a una minoría de hombres. De este modo, aquellos que tienen un supremo entendimiento son los que se encuentran predispuestos a recorrer el camino de las ciencias. Semejante idea aparece postulada en una suerte de teoría de los orígenes del hombre y del mundo:

Et non obstant que Philosophie avec ses filles fust avant que moy et que fille de Dieu soit, si fus je faicte aussi tost que creé fu entendement humain. Et lui et moy ouvrimes la voie aux hommes de clerengin a la trouver, a entendement premier et moy seconde (Livre de l'advision, II.3: 55).

Y no obstante que Filosofía junto a sus hijas fue creada antes que yo, y que asimismo es hija de Dios, yo también fui creada al mismo tiempo que entendimiento humano. Y juntos abrimos la vía a los hombres de claro ingenio para encontrarla; hacia el entendimiento primero y a mi segunda (Livre de l'advision, II.3).

En palabras de Conocimiento ("Dama Opinión") Christine nos informa cómo con el hombre nacen en simultáneo el entendimiento y las ciencias. Adviértase sin embargo que nuevamente aparece el criterio selectivo, puesto que, si el entendimiento es la disposición para alcanzar las ciencias y a través de ellas la filosofía, este entendimiento solo pertenece a los "hombres de claro entendimiento". Como corolario, adjetivos como "sutil", "sabios" y "clarividentes" suelen acompañar las referencias a estos individuos que poseen el entendimiento idóneo para alcanzar el conocimiento metafísico. Por esto mismo, no es de extrañar la presencia de los clérigos universitarios dentro de este último grupo; aquellos "grandes doctores con un entendimiento tan elevado y profundo, tan clarividentes en todas las cosas" (La citédes dames I.1). ${ }^{7}$ No caben dudas de que para Christine los entendimientos faltos de sutilidad no entran dentro de su teoría de entendimiento, puesto que lo que aparece definiendo al entendimiento es precisamente dicha capacidad para arribar al conocimiento científico, a la episteme - por definición- especulativa. Debemos entonces insistir en este punto: para Christine, "la nobleza de entendimiento" no es un hábito universal sino una disposición otorgada a unos pocos hombres:

Avec sapience et science est neccessaire don d'entendement à perfaitte sagece, c'est assavoir homme sage. Or soit notté se cellui que nous disons si sage, qui est à m'entencion le roy Charles, pot avoir, avec les biens dessus ditz, la noblece d'entendement (Livre des fais, III.5: 203).

\footnotetext{
6 Christine de Pizan, Livre de ladvision, II.22: 88: "Dame, puisquil est ainsi que de vous vient la premiere invencion des œuvres humaines bonnes ou males, rudes ou soubtilles selon la disposicion des entendemens" [Dama, porque dado que de vos proviene la primera invención de las obras humanas, buenas o malas, groseras o sutiles según la disposición de los intelectos].

7 Christine de Pizan, La cité des dames I.1: 36: "grands docteurs à l'entendement si haut et profond, si clairvoyants en toutes choses".
} 
La perfecta sabiduría, aquella del hombre que llamamos sabio, exige además de la sabiduría especulativa y la ciencia, el don de entendimiento. Veamos, entonces, si aquel que tenemos por tal sabio, es decir, el rey Carlos V, tenía, junto a dichas cualidades, la nobleza de entendimiento (Livre des fais, III.5).

Esta "nobleza de entendimiento" se resume en la capacidad de especular-de conceptualizar- que representa la esencia de la episteme. Sin duda, Carlos V posee el hábito del entendimiento que le permite alcanzar la máxima ciencia que es la ciencia divina: "Podemos ya concluir que, entre los elegidos, aquel rey era muy soberano y superlativo por el don de entendimiento" (ibid.). ${ }^{8}$ Así, la concepción del entendimiento vertida por la escritora permite la equiparación del rey con los clérigos que manejan la episteme y que se dedican a la dialéctica. Sin embargo, consideramos importante subrayar que la idea de un rey construido como un clérigo, no implica en modo alguno la reproducción de un elitismo clerical, ni de tipo sociológico ni de tipo científico. Antes que un elitismo clerical, preferimos hablar de un elitismo intelectual o en todo caso de un proceso que entraña toda una nueva conceptualización del término clérigo.

\subsection{El intelecto del rey: de la clericatura a la política}

Sostenemos que existen dos ideas que explican el fenómeno del elitismo intelectual dentro del pensamiento de la autora: 1 . La idea de un rey clérigo que maneja a la perfección la episteme; aquel dominio que la sociedad reconoce como exclusivo de los clérigos universitarios; 2 . La idea de un rey prudente que coloca la episteme al servicio del Estado. Desde un primer momento debemos decir que ambas ideas no son opuestas, sino por completo complementarias. En efecto, la primera premisa aparece como condición de la segunda premisa; mientras que la segunda transforma asimismo el significado de la primera.

\subsubsection{El rey "dialecticien"}

La idea de un rey con un entendimiento superlativo permite alcanzar el núcleo duro de la clericatura universitaria. El desarrollo que hace Christine del entendimiento sustenta la idea de un rey construido a imagen y semejanza de un clérigo universitario. ¿Acaso no es la dialéctica la ciencia que mejor representa a los maestros universitarios? ¿No eran las ciencias, sobre todo, alcanzables a partir de la lógica? Christine parece responder a nuestras preguntas con la referencia a Alberto Magno. Para este autor escolástico, aquel que ignora la lógica ignora también las razones de lo que sabe: "Alberto Magno dice al respecto: 'Quien ignora la lógica, ignora el porqué de lo que sabe"' (Livre des fais, III.64). ${ }^{9}$ Indudablemente, desde el momento en que el rey posee un entendimiento superior que le permite desarrollar las ciencias, es que puede equipararse a un maestro universitario. Es el entendimiento lo que termina por equipararlo a los sabios doctores, en tanto alcanza la esencia de la episteme, es decir, el conocimiento especulativo desarrollado a partir de la dialéctica: "Admiremos la sutileza del intelecto de nuestro príncipe, la gran aplicación que pone para comprender y aprender todas las disciplinas, tanto especulativas como prácticas, cuando estudia las ciencias nobles" (ibid., III.5). ${ }^{10}$

Es precisamente esta capacidad de conceptualizar todos los saberes, es decir, de extraer máximas científicas lo que define al entendimiento. De este modo, el rey ejerce el rol de architector en tanto conocedor de las causas (Iogna-Prat y Rodriguez, 2017). Luego, la especulación científica, como exige la costumbre académica, ha de llevarse a

8 Christine de Pizan, Livre des fais, III.5: 204: "Si povons de cellui Roy conclurre, que entre les esleus estoit tres souverain et suppellatif en haultece d'entendement”.

9 Ibid., III.64: 295: "dont ce dit Albert: Qui logique ne scet, il ne scet soy savoir ce quil scet".

10 Christine de Pizan, Livre des fais, III.5: 203: “Or regardons la subtillece de lentendement de nostre prince, comment grandement s'estendi à comprendre et concepvoir toutes choses, tant speculatives, comme ouvrables, lorsque les belles sciences estudioit". 
cabo por medio de la dialéctica durante las reuniones y colaciones universitarias. No es de extrañar que luego de exponer su teoría del entendimiento, la autora muestre al rey participando del ejercicio dialéctico junto a los maestros universitarios: "él poseía perfectamente el vocabulario y lo usaba plenamente con los grandes maestros y filósofos en sus reuniones y asambleas. Hablaba tan bien y tan profundamente que nadie lo superaba" (Livre des fais, III.5). ${ }^{11}$

Hoy en día, sabemos que para la enseñanza universitaria parisina de los siglos XIV y XV, dentro de las siete artes liberales, primaba la dialéctica. ${ }^{12}$ Por ende, al poseer un entendimiento sutil, el rey podía fácilmente participar de las actividades académicas propias de los filósofos universitarios. Más aún, según la autora, existían pruebas y testimonios de que Carlos V era un excelso "dialéctico"; el mejor -a quien "nadie superaba"- entre todos los eminentes maîtres y doctores de la Universidad de París.

Llegados a este punto nos permitimos avanzar un poco más en el razonamiento. Sin duda la teoría del entendimiento formulada por Christine aparece como un elemento indispensable para la figuración del monarca como rey clérigo (maître universitario). Lo vemos alcanzando la episteme, especulando y ejerciendo la dialéctica en el marco de las colaciones universitarias, superando incluso en el ejercicio a los eminentes doctores, "solemnes clérigos". No obstante, el intelecto del rey también aparece realizando el camino inverso: de lo especulativo a lo contingente, con unas ciencias especulativas que antes de ser pura teoría son ejercidas por el rey en el marco de la función real, a la par que adquieren incontestable utilidad pública. Es oportuno ahora preguntarnos por el vínculo entre el entendimiento y la política. En otras palabras, ¿en qué medida el entendimiento del soberano -intelecto científico- puede ser puesto al servicio del Estado?

\subsubsection{Entendimiento y política}

A nuestro parecer, dos cuestiones vienen a marcar la idea de un entendimiento al servicio de la política. En primer lugar, la teoría de los "elegidos" por gracia divina ("nobleza de entendimiento"), anclada en los capítulos dedicados a mostrar el pasaje de la juventud a la madurez del rey. ¿Por qué? Precisamente porque dicho pasaje no es más que la transformación del heredero al trono en rey coronado (Rodriguez, 2020). En este sentido, podemos considerar que la idea de un entendimiento superior se arraiga en la función regia y no en el ejercicio de la ciencia asimilado a la mera contemplación.

En efecto, un heredero convertido en el primer servidor de la Corona ha de tener un entendimiento superior que le permita superar las fragilidades propias de la edad. Su deber es gobernar por medio de la ciencia política la cual ha aprendido-llegando a ser un "experto en dicha ciencia"-gracias a su "perspicaz entendimiento" (cf. Livre desfais, I.19: 68). Desde esta perspectiva, el entendimiento supremo le permite al rey alcanzar la episteme al tiempo que adquirir la ciencia política. Por lo demás, la teoría del entendimiento a partir de una categoría sociológica -aquella de los "elegidos"-y anclada en los capítulos abocados a la conceptualización de la función real nos hablan de un intelecto regio cuya operatividad está al servicio de la política. Las distintas ciencias del trivium et quadrivium vienen a comprobar la idea de unas ciencias cuya finalidad no es otra que el soberano bien común. Al respecto, ya se expresaba Dante en un pasaje del De monarchia:

11 Ibid., III.5: 203-204: “desquelles les termes savoit plainement raporter ez assemblées et congregacions des sages maistres et philosophes, parler de toutes choses si bien et si parfondement que nul ne le passoit". 
Est ergo sciendum quod quedam sunt que, nostre potestati minime subiacentia, speculari tantummodo possumus, operari autem non: velut mathematica, physica et divina; quedam vero sunt que, nostre potestati subiacentia, non solum speculari sed etiam operari possumus: et in hiis non operatio propter speculationem, sed hec propter illam assummitur, quoniam in talibus operatio finis. Cum ergo materia presens politica sit, ymo fons atque principium rectarum politiarum, et omne politicum nostre potestati subiaceat, manifestum est quod materia presens non ad speculationem per prius, sed ad operationem ordinatur (De mon., I.2: 80).

Pero hay que saber que hay materias que escapan casi totalmente a nuestro poder, sobre las cuales podemos especular pero no actuar; por ejemplo, las realidades matemáticas, físicas y divinas. Pero hay ciertamente algunas, sometidas a nuestro poder, que pueden ser para nosotros no solamente objeto de especulación sino también de operación: en estas no es la operación que deriva de la especulación sino la especulación la que deriva de la operación, ya que en tales materias la operación es un fin. Puesto que la materia presente es la política, más exactamente la fuente y el principio de las constituciones rectas, y que todo lo que es política depende de nuestro poder, es evidente que la materia presente se ordena en prioridad, no en vistas de la especulación sino en vistas de la operación (De mon., I.2).

Desde este enfoque, ¿acaso el entendimiento elevado del rey no está al servicio de poder conceptualizar, incluso las ciencias más difíciles para luego poder ponerlas al servicio de la política? Al respecto, cabe recordar la prioridad que Christine otorga al ejercicio de las ciencias antes que a las definiciones, sobre todo en la ciencia más especulativa de todas, la ciencia divina. Para poner los saberes más difíciles al servicio de la política, el rey ha de hacerlo mediante un entendimiento superior, apareciendo, este, como el único medio para hacer el traspaso de las ciencias especulativas al registro de lo contingente.

Luego, el medio de dicho pasaje es la virtud de la prudencia. De este modo, el entendimiento aparece asimismo como la condición de un rey prudente, que sobrepasa el registro de una prudencia meramente empírica para alcanzar el campo de la episteme. En efecto, tanto las ciencias como la prudencia tienen su origen en el entendimiento. El vínculo entre el entendimiento (vehiculizado por la teoría de la gracia en torno a los entendimientos superiores), las ciencias y la prudencia queda de manifiesto en el capítulo destinado a hablar de la prudencia en el Livre de la paix.

Si seguimos el razonamiento de la escritora, notamos que el entendimiento es la primera disposición del alma racional, que difiere según los hombres, ya que no es dada a todos por igual: "que entendimiento, que es potencia y operación del alma, dice San Agustín, es donado por Dios, singularmente, en mayor medida a ciertos hombres que a otros" (Livre de la paix, I.5). ${ }^{13}$ Por su parte, el rol del entendimiento es el de procesar tanto las cosas captadas por los sentidos como las meras cosas especulativas con el objeto de investigarlas y engendrar así el conocimiento. Este conocimiento nos otorga una mejor comprensión de las cosas prácticas, es decir, de las cosas que queremos realizar y de las maneras de llevarlas a cabo:

l'office de cest entendement est d'ymaginer toutes choses veues ou non veues; selon la quantité de sa force pour lesquelles ymaginacions par bien invistiguer est engendree congnoissance, laquelle s'aproche plus des choses ouvrables, c'est assavoir des choses que on veult mectre a euvre, congnoistre et entendre les manieres de les faire et entreprendre (Livre de la paix, I.5: 208).

13 Christine de Pizan, Livre de la paix, I.5: 208: "qu'entendement qui est puissance et operacion de l'ame, si que dit Saint Augustin, de Dieu donné singulierement plus grant es uns hommes que es autres". 
la función del entendimiento es aquella de imaginar todas las cosas vistas y no vistas; de acuerdo con la capacidad de su imaginación para investigar bien, el conocimiento es engendrado. Este conocimiento trae una mayor comprensión de las cosas prácticas; esto es, de las cosas que uno busca alcanzar, y el conocimiento para obtenerlas (Livre de la paix, I.5).

En resumidas cuentas, el entendimiento aparece como aquella disposición que permite al rey: 1) el aprendizaje de la episteme, 2) el ejercicio de la dialéctica en el marco universitario, 3) el aprendizaje de la política para el gobierno del reino. Asimismo, estas tres premisas, en la persona del rey sabio de Christine, vehiculizan nuevos postulados con trazos sumamente originales. La capacidad de alcanzar la episteme permite al rey equipararse a un mâtre universitario que sobrepasa en dialéctica a los más solemnes de entre todos ellos. No obstante, los tipos de ciencias impartidos por este rey no son los acostumbrados en la cultura clerical sino unos saberes de nuevo cuño en donde tanto los métodos, contenidos y finalidades se presentan modificados. Mientras que la construcción y la política entran dentro del rango de la episteme, los saberes netamente especulativos adquieren un carácter práctico tanto en sus métodos como en su finalidad, tal como hemos estudiado para el caso de la filosofía, la astrología y las artes liberales. Finalmente, la teoría de los elegidos por gracia divina, anclada en el concepto de función regia junto a la imagen del rey como intelecto del cuerpo de la política, no puede más que reconducir las ciencias -trabajadas en el libro III- al campo de la política. En síntesis, si el entendimiento predispone al rey para la episteme, falta aún tratar sobre aquella virtud que permite el pasaje de las ciencias al campo de la política; nos referimos a la prudencia.

\section{Prudencia}

\subsection{La phronesis medieval}

A menudo, en la actualidad, los académicos de la Baja Edad Media concuerdan en identificar la prudencia como una "sabiduría práctica", hecho que implica una completa asimilación entre prudencia y política (Chopin-Pagotto, 1999; Autrand, 2009). Esta concepción presente en los espejos de príncipes -del siglo XIII en adelante- fue el resultado de un doble movimiento. Por un lado, el avance de la centralización monárquica y el aumento de las funciones del rey. Por el otro, la introducción de la Ética y de la Política de Aristóteles en el Occidente cristiano.

En este contexto, con un reino comprendido como una comunidad política, el adagio regio de gobernarse a sí mismo para gobernar a los demás dejó de ser suficiente (Chopin-Pagotto, 1999: 91). Dado que el ejercicio de gobierno se había convertido en un arte (un complejo de principios y códigos propios que el rey debía dominar a la perfección), el gran desafío de los nuevos espejos fue desarrollar el "sentido político" del príncipe (ibid., 88-89). La principal función del monarca no se orientaba, ya, a la salvación individual de las almas de sus gobernados, sino a la conducción del cuerpo político hacia la meta del bien común, que había dejado de estar vinculada -al menos de modo directo- con la salvación. Fue esencialmente gracias a la recuperación de la phronesis aristotélica por medio de Tomás de Aquino, que la prudencia se convierte, hacia finales del siglo XIII, en la virtud política por antonomasia. ${ }^{14}$

La interpretación política de la prudencia hizo que progresivamente fuese abandonando su significado religioso, ligado a la discreción y a la moderación de la ética monástica. Siguiendo los postulados aristotélicos de la Ética, el Aquinate se refería a la prudencia como "recta ratio agibilium". De una manera general, pertenece a la virtud de la prudencia determinar cómo y mediante cuales medios, el hombre que actúa, 
puede alcanzar la medida de lo razonable. Ella es presencia actuante de la razón en el seno de un apetito y de las pasiones, que muestra el fin perseguido y los medios más adecuados para alcanzarlo. Por esto mismo, es la justa medida de las acciones a emprender (Daguet, 2017: 179-183).

Ciertamente, la recuperación de la phronesis aristotélica iniciada por Tomás de Aquino era parte de un proceso más vasto en el cual el complejo de virtudes antiguas de la patrística comenzaba a desarroparse de su tradicional carácter cristiano para pasar a ser pensadas en base al concepto de reino como comunidad natural (Hibbs, 2001). Pronto, el príncipe -como cabeza de la comunidad política-se volvió acreedor de estas virtudes leídas en clave secular, entre las cuales la prudencia comenzaba a ocupar un lugar destacado. Incluso ya en su Summa Theologiae, Santo Tomás hacía referencia a la prudencia "regnativa" como la más perfecta, por ser la prudencia que competía especialmente al príncipe. Ella es la más perfecta de todas porque encontramos una suerte de gobierno eminente y perfecto en aquel que no solo debe conducirse a sí mismo, sino que también debe gobernar la sociedad perfecta que es una ciudad o un reino. ${ }^{15}$

Nicolás Oresme, el gran traductor y comentarista del corpus aristotélico de la corte de Carlos V, de quien Christine había leído las últimas traducciones de la Política y la Ética, ya se había percatado de la distinción entre phronesis y sabiduría en el pensamiento del Estagirita. De ahí, que Oresme indicase que para gobernar la sabiduría se mostraba insuficiente, si no era acompañada de esa virtud moral y práctica llamada prudencia (L. de éthiques d'Arist:: 360). En tanto proviene de la razón práctica, la prudencia es una virtud intelectual. En tanto se extiende hasta la aplicación de la obra, la prudencia releva asimismo de la voluntad, tal como lo exponía Tomás de Aquino.

No sin razón, al estudiar el valor que para los escritores bajomedievales poseía la prudencia, historiadores contemporáneos como Françoise Autrand catalogaron a la prudencia como un tipo de sabiduría práctica: "La sagesse, quand il s'agit d'action politique, prend la forme de la prudence" (2009: 236). La asimilación entre política y prudencia encuentra su justificación en el hecho de que el príncipe ha siempre de actuar prudentemente sea cual sea el contenido de las diversas acciones. En efecto, la construcción de lo político en Christine de Pizan viene a condensar muchos de los aspectos de la phronesis bajomedieval, aunque como veremos su campo de acción excede el marco de lo meramente contingente. ¿Cuál es entonces la definición de prudencia provista por la escritora?

\subsection{Una definición "en dichos" por medio de las auctoritates}

Ante todo, la prudencia es uno de los elementos que constituyen la "perfecta sabiduría" junto a la metafísica, las ciencias, el entendimiento y el arte. Siguiendo el libro VI de la Ética a Nicómaco la autora define a la prudencia como una virtud intelectual que se encuentra alojada en la parte práctica del alma junto al arte. No obstante, si tanto arte y prudencia tratan sobre cosas contingentes, el terreno de esta última se encuentra en las acciones humanas y no en la producción de objetos (cf. Livre des fais, III.2: 198).

15 Tomás de Aquino, STh II-II, q. 50, a. 1: "Respondeo dicendum quod sicut ex supradictis patet, ad prudentiam pertinet regere et praecipere. Et ideo ubi invenitur specialis ratio regiminis et praecepti in humanis actibus, ibi etiam invenitur specialis ratio prudentiae. Manifestum est autem quod in eo qui non solum seipsum habet regere, sed etiam communitatem perfectam civitatis vel regni, invenitur specialis et perfecta ratio regiminis, tanto enim regimen perfectius est quanto est universalius, ad plura se extendens et ulteriorem finem attingens. Et ideo regi, ad quem pertinet regere civitatem vel regnum, prudentia competit secundum specialem et perfectissimam sui rationem. Et propter hoc regnativa ponitur species prudentiae" [Respondo diciendo, como se desprende de lo dicho arriba, que a la prudencia concierne el dirigir y el prevenir. Y por esto, en donde es encontrada la razón especial de gobierno y de los preceptos en los actos humanos, allí también se encuentra la razón especial de la prudencia. Resulta evidente, sin embargo, que en el que no solo se tiene a sí mismo para conducir, sino también a la comunidad perfecta de la ciudad o del reino, se encuentra la perfecta razón especial del regimen, pues el gobierno es tanto más perfecto cuanto más universal, extendiéndose hacia muchas cosas y alcanzando el último fin. Y por esto para el rey, a quien concierne dirigir la ciudad o el reino, la prudencia se deriva de su especial y más perfecta razón. Y por esto se define esta clase de prudencia regnativa]. 
Luego, a lo largo de la obra la autora va ensanchando su definición de prudencia, con motivos que tratará con mayor o menor ahínco en el resto de sus escritos políticos.

En grandes líneas, su definición de prudencia abarca toda una serie de elementos comunes a la tratadística política bajomedieval, en particular, presentes en los espejos de príncipes como el De regimine principum o en las traducciones aristotélicas como las realizadas por Nicolás Oresme. Al respecto, podemos citar seis componentes esenciales de la prudencia en la obra de Christine de Pizan:

1. La prudencia como virtud intelectual en el plano de lo contingente tomada de la definición aristotélica del VI libro de la Ética: "ya que la prudencia concierne a las acciones que no suceden en materia externa, sino que son acciones puras" (Livre desfais, III.2). ${ }^{16}$

2. La idea de prudencia como madre y guía de todas las virtudes en el Livre des fais: "Y como la prudencia y la sabiduría son madres y directoras de las otras virtudes" (ibid., I.22). ${ }^{17}$ De igual modo, aunque bajo el nombre de discreción en el Livre de la paix: "Discreción (prudencia) que es madre y directora, y entre todas las virtudes, la primera" (ibid., I.5). ${ }^{18}$

3. La prudencia como acto de deliberación medios-fines (consejo).

4. Su carácter moral en tanto aplicación de la obra:

selon les termes d'Aristote, qui dit que prudence est es hommes ce quilz deliberent par raison des choses agibles, dont proprement prudence est rigle de conseil; si que, où est nature consiliative, proprement est prudence, car il convient que quiconques conseille premierement conceve aucune fin, et puis, qu'il enquiere les choses duisans à celle fin, c'est assavoir, en conferent entre elles, lesquelles sont celles qui valent mieulx ou pis, et ainsi toute poissance consiliative est prudence (Livre des fais, III.66: 297-298).

la definición que ofrece Aristóteles es la siguiente: la prudencia es aquello que hace que los hombres deliberen razonablemente sobre aquello que concierne a las acciones. La prudencia es, propiamente hablando, el principio de la deliberación. Allí donde debemos elegir, es precisamente donde se encuentra la prudencia, dado que hace falta que aquel que delibera conciba previamente algún fin, y que busque luego la manera de alcanzarlo. Hace falta, así, comparar los medios de los que se dispone y saber cuáles son los más y los menos favorables. Así, cada vez que buscamos deliberar, apelamos a la prudencia (Livre des fais, III.66).

5. La prudencia como conocimiento no libresco sino primordialmente empírico, tal como lo remarca el adagio "debemos confiar en aquel hombre prudente hecho por su experiencia" (Livre des fais, I.13). ${ }^{19}$ La misma idea se repite en el Livre de la paix, en la parte en que la autora aclara que los clérigos expertos en ciencias no siempre son los más prudentes en el campo de la política (ibid., I.7: 212).

6. La idea de prudencia como prévoyance (previsión), que permite al hombre prudente prevenir el futuro: "Dice Juvenal: 'Prudencia previene los tiempos venideros $y$, por lo tanto, quien la posee adquiere la deidad. Respecto a lo cual concuerda Boecio: 'No es suficiente con conocer las cosas presentes sino aquellas futuras"' (Livre de la paix, II.4). ${ }^{20}$

16 Christine de Pizan, Livre des fais, III.2: 198: "car prudence adrece aux accions qui ne passent pas en matiere dehors, mais sont accions perfaittes".

17 Ibid., I.22: 72: "Et comme prudence et sagece soit mere et conduisseresse des aultres vertus".

18 Christine de Pizan, Livre des paix, I.5: 209 "Discrecion (prudence) qui est dicte mere et conduisarresse et toute la premiere des vertus".

19 Christine de Pizan, Livre des fais, I.13: 56: "cellui qui y est prudent doit estre creu en son experience".

20 Christine de Pizan, Livre de la paix, II.4: 235-236: "Et pour ce disoit Juvenal: 'Prudence pourvoit au temps a venir et pour tant a aquise deité qui l'a. Ce acorde Bouece disant: Il ne souffist pas congnoistre les choses presentes mais celles a venir ou qui avenir 
A grandes rasgos estos seis elementos se encuentran condensados en la definición ciceroniana de prudencia que la autora evoca en su capítulo dedicado a la prudencia en el Livre des fais. Allí, Christine reproduce la fórmula de la segunda Retórica de Cicerón (probablemente tomada de la traducción De inventione de Juan de Antioquia de 1282, (Musée Condé, ms. 590) que permite discernir las partes constitutivas de la prudencia "ya que, según Cicerón, en la segunda de sus Retóricas, 'las partes de prudencia son:memoria, inteligencia y previsión" (Livre des fais, III.6). ${ }^{21} \mathrm{~A}$ menudo las referencias a Cicerón nos hablan de la primacía de lo concreto, de la experiencia. ¿Pero hemos de reducir, entonces, la prudencia de Christine, meramente, a una virtud de lo contingente?

Llegados a este punto es necesario hacer una serie de aclaraciones. La fuerza de la experiencia, de lo concreto, no debe hacernos perder de vista la relación entre prudencia y episteme en el modelo político planteado por la escritora. Hemos de tener cuidado de otorgar a las definiciones de Christine el mismo significado que las auctoritates y en especial el mismo significado que ciertos espejos de príncipe, como aquel de Egidio Romano. Por ende, no podemos establecer a la prudencia como simple virtud de lo contingente, puesto que corremos el riesgo de perder de vista su vínculo con el saber especulativo.

Este es el riesgo a correr si caemos en razonamientos como los sostenidos por Daisy Delogu, quien dejándose llevar por las definiciones de prudencia a partir de la Ética aristotélica y de las Retóricas ciceronianas compartidas por Egidio Romano y Christine, atribuye a todos estos autores una actitud similar respecto a la episteme y a la teoría. En su artículo Christine de Pizan, lectrice de Gilles de Rome (2008), la autora habla de la primacía de la práctica por sobre la teoría. Esta primacía de la práctica se explicaría por la admiración de Egidio y de otros autores hacia la Ética de Aristóteles, donde el Estagirita diferencia la episteme del conocimiento práctico (phronesis). Según la autora, Christine logra captar bien este registro y opera de modo semejante a Egidio Romano, jerarquizando lo práctico sobre la teoría y distinguiendo los conocimientos científicos (episteme) de la sabiduría práctica (phronesis). Para sustentar esta idea nada mejor que la referencia a Cicerón, para quien la más alta sabiduría era aquella que tenía como objetivo un resultado concreto. Para el caso específico de Egidio Romano, Daisy Delogu señala que esta diferencia entre episteme y phronesis puede verse en la gran distancia que separa el saber y el hacer en aquellos pasajes del De regimine que nos hablan de un conocimiento preciso. ${ }^{22}$ En cuanto a Christine, concluye: "La même tendance à privilégier les effets plus que la source et les actions plus que l'acteur [...] Cette mise en valeur des actes et des conséquences peut mener à un pragmatisme quelque peu surprenant" (2008: 223).

Coincidimos en muchas de las premisas, en torno a la prudencia, sostenidas para la Baja Edad Media, principalmente aquellas provenientes del aristotelismo político de autores como Egidio Romano. Concordamos en principio con la imagen de un rey ideal deducible de los hechos. Asimismo, estamos absolutamente de acuerdo con la idea de una prudencia asimilable a la política y con su rol de guía de la conducta regia. Sin embargo, nos permitimos disentir con la idea de una prudencia separada de la episteme, como también de aquella concepción que ve a la prudencia como una simple sabiduría práctica. Al menos en lo que atañe a Christine, no parecen cumplirse dichas

21 Christine de Pizan, Livre des fais, III.6: 204 “car, selon Tulle, ou .IIe. des siennes Rethoriques, les parties d'elle sont mises: memoire, intelligence, et pourveance".

22 Delogu, 2008: 221: "L'insistance de Gilles sur l'importance des exemples et l'exemplarité va de pair avec sa hiérarchisation de la pratique sur la théorie. On peut remarquer à cet égard son admiration pour l'Éthique d’Aristote, où le Philosophe distingue les connaissances scientifiques (episteme) de la sagesse pratique (phronesis). Le privilège accordé à cette dernière pourrait remonter à Cicéron, pour qui la plus haute sagesse est celle qui a pour objectif un résultat concret". 
premisas. Por el contrario, la episteme está estrechamente vinculada a la práctica, y la prudencia se eleva hasta un registro metafísico, tal como tendremos la oportunidad de apreciar a continuación. No hay que olvidar que, si Christine tiene como fuente la Ética de Aristóteles y la Segunda Retórica de Cicerón, también recupera el saber aristotélico de la Metafísica y del De Anima a través de Tomás de Aquino, y probablemente también tenía conocimiento del De monarchia de Dante. Allí, la noción de intelecto y de potencia intelectual parece dar con la clave a las cuestiones aquí planteadas.

\subsection{Entendimiento, prudencia y episteme}

Si nos guiamos por la definición y el lugar central del entendimiento en el Livre des fais, es difícil quedarse en el mero registro empírico de la prudencia. De ahí, que la definición ciceroniana con hincapié en lo concreto merezca una relectura. No olvidemos que, como partes constitutivas de la prudencia, junto a la memoria (experiencia) y la previsión, también se encuentra la inteligencia.

En rigor, luego de todo el desarrollo que hicimos del entendimiento, la inteligencia ciceroniana adquiere otro cariz. En principio, el entendimiento y la prudencia aparecen unas veces tratados en los mismos capítulos del Livre des fais, otras veces en capítulos separados pero contiguos. En principio, porque la prudencia proviene del entendimiento. En otras palabras, es esa parte del entendimiento que permite el conocimiento de las cosas prácticas. En este sentido, la escritora sigue a Aristóteles, para quien la prudencia releva de los universales como de los casos particulares y por ende es una virtud que se mueve en ambos registros (universal-particular), aquel de la ciencia y aquel de las acciones humanas. Por lo tanto, la prudencia adquiere en gran medida las cualidades especulativas del intelecto, aunque con una primacía de la acción. En este sentido, Christine pareciera seguir a Dante, quien en su De monarchia habla de la primacía del entendimiento por su doble cualidad:

Potentia etiam intellectiva, de qua loquor, non solum est ad formas universales aut speties, sed etiam per quandam extensionem ad particulares: unde solet dici quod intellectus speculativus extensione fit practicus, cuius finis est agere atque facere. Quod dico propter agibilia, que politica prudentia regulantur, et propter factibilia, que regulantur arte: que omnia speculationi ancillatur tanquam optimo ad quod humanum genus Prima Bonitas in esse produxit; ex quo iam innotescit illud Politice: intellectu, scilicet, vigentes aliis naturaliter principari (De mon., I.3: 86).

Además, la potencia intelectiva de la cual hablo se extiende no solamente a las formas universales o las especies, sino, por una extensión determinada, a las formas particulares. Es por lo cual se suele decir que el intelecto especulativo deviene por extensión intelecto práctico, cuyo fin es el de actuar y hacer. Digo esto, pensando en cosas que relevan de la acción, las cuales son regidas por la prudencia política, y a esas cosas que relevan del hacer, que son regidas por el arte: todas las cosas que están sometidas a la especulación, como a la mejor cosa por la cual la Primera Bondad hizo venir el género humano al ser. Lo cual a partir de aquí distingue las palabras de la Política: aquellos que poseen el vigor del intelecto reinan naturalmente (De mon., I.3).

No es de extrañar entonces que Christine hable de la política como una ciencia que el rey aprende por medio de su prudente intelecto "por la prudencia de su perspicaz entendimiento, la aprendió naturalmente, sin jamás haberla estudiado en los libros" (Livre desfais, I.19). ${ }^{23} \mathrm{Al}$ respecto, esta idea de intelecto especulativo que por extensión se transforma en intelecto práctico resulta crucial para entender el carácter político que adquiere la episteme en el pensamiento de Christine de Pizan. La prudencia en

23 Christine de Pizan, Livre des fais, I.19: 68: "par la prudence de son averti entendement, lui apprenoit naturelement, sanz autre estude de lettreure aprise en ceste partie". 
tanto virtud intelectual y moral permite el pasaje de las ciencias llamadas especulativas al campo de la política. Por lo demás, no debemos olvidar que siguiendo la metafísica aristotélica la ciencia tiene en la mayoría de los casos un componente empírico. En síntesis, nos interesa subrayar que, si las ciencias del quadrivium y del trivium adquieren un significado político en el pensamiento de la autora, es gracias a la prudencia que logra bajar a lo contingente de los asuntos políticos, el conocimiento producido por la parte especulativa del intelecto.

Cabe ahora tratar de explicar la diferencia entre Egidio Romano y Christine de Pizan respecto a la relación entre phronesis y episteme. Si en Egidio la distancia entre episteme y hechos es grande, creemos que es porque el autor no genera una episteme al servicio de la política, como si lo hace Christine. Mientras el agustino nos habla del conocimiento jurídico -gramática (leyes) / retórica- para el rey en ejercicio de sus funciones, Christine abarca todo el abanico de ciencias liberales, artes, la jurisprudencia y sobre todo la metafísica.

El rey sabio de Christine es un rey que porta un entendimiento superior en ambos sentidos: para la episteme y para las ciencias prácticas. Luego, la virtud de la prudencia es lo que le permite volcar a la práctica las ciencias especulativas. En este sentido, Carlos $\mathrm{V}$ aparece como un rey científico que actúa en el plano de lo contingente gracias a la prudencia regia. No obstante, cabe preguntarse si el vínculo entre prudencia y episteme radica únicamente en la prudencia como mero medio, un canal que va desde el conocimiento especulativo al conocimiento práctico volcado en los asuntos políticos. Nuevamente, este no parece ser el caso. Si salimos del mero registro de la prudencia definida en la Ética y en la Segunda Retórica ciceroniana y nos sumergimos en los conceptos de la Metafísica, del De anima pero también de la misma Política de Aristóteles, retomadas por Tomás y Dante, podemos ver el panorama con una nueva luz.

Por ejemplo, en el Livre des fais como en el Livre de la paix la escritora se refiere a la prudencia como aquella virtud que le permite al príncipe distinguir el bien del mal:

de ceste discrecion (prudence), de quoy elle sert ou puet servir, dist l'Ecclesiaste que c'est une vertu par laquelle se puet congnoistre ce que est bon et ce que est mauvais en discernant le bien du mal, et en l'election du bien pour ce que il est valable et deboutant le mal pour ce qu'il est nuisible (Livre de la paix, I.5: 209).

de esta discreción (prudencia), y para lo que debe servir, dice Eclesiastés que es una virtud por la cual se puede conocer lo que es bueno y lo que es malo, discerniendo, así, el bien del mal; eligiendo el bien porque es valioso y desestimando el mal porque es dañino (Livre de la paix, I.5).

Probablemente Christine recupere la versión de prudencia de Alain de Lille, quien se explaya sobre las cuatro virtudes cardinales en su tratado De Virtutibus et de vitiis et de donis Spiritus Sancti. Allí el autor define a la prudencia como "discepcion de bonnes et mauvaises choses en la fuyte du mal et l'election du bien" (discernimiento de las cosas buenas y malas para la huida del mal y la elección del bien) (cf. Green, 2008: 23).

No podemos pasar por alto la influencia de los comentarios de la Metafísica de Tomás de Aquino, quien hace de la virtud política una rama de la teología y de la prudencia una virtud que sirve para determinar tanto los asuntos espirituales como corporales del hombre. En este sentido, la prudencia es la virtud que permite alcanzar el máximo bien, que en Tomás adquiere un viso trascendental, un más allá de la vida en comunidad política (Daguet, 2017: 50). Este fin, a medio camino entre el mundo terrestre y el celeste, marca la unidad entre la política y la ética ya presente en Aristóteles. 
En el Livre des fais la cuestión es más enrevesada y los argumentos de Christine se concentran en el concepto del entendimiento o intelecto del rey, especie de maximización de todo el conocimiento, incluidas la prudencia y la episteme.

\subsection{El entendimiento del rey como intelecto de la comunidad política}

La prudencia deriva del entendimiento, tal como puede asimismo apreciarse en el Livre desfais, cuando se produce el pasaje de la juventud a la madurez, es decir, del hombre joven y sin juicio al hombre maduro, prudente y sabio: "Ahora ve claro lo que era confuso; le viene a la memoria toda la experiencia de las cosas vividas que ha visto, por lo que puede, por primera vez, juzgar con conocimiento de causa" (ibid., I.13). ${ }^{24}$ Lo interesante en el Livre des fais es que dicha prudencia comprendida de una manera trascendental (distinción del bien y del mal) incluye el conocimiento de la episteme:

or cognoist la verité et droitte operacion de tout quan que il a retenu et apris en son enfance et jeunece; adonc cognoist et scet demoustrer les causes du vray; or scet-il donner doctrine comme expert et instruit de ce qui lui est apparu ou cours de sa vie, soit en science ou autre exercite qu'il ait veu et continué, se il est homme apris es sciences (Livre des fais, I.13: 56).

ahora conoce la verdad y el buen uso de todo cuanto ha aprendido y retenido desde su infancia y juventud; ahora conoce y sabe demostrar las causas de lo verdadero; ahora sabe, asimismo, en tanto experto y hombre instruido, impartir a otros la doctrina de todo lo que aprendió a lo largo de su vida, sea en materia de ciencias o en cualquier otra actividad que hubo de conocer o ejercer (Livre des fais, I.13).

En realidad, lo que transmite dicho pasaje, no es más que las distintas capacidades del hombre sabio una vez alcanzada la madurez (estipulada en los 50 años de acuerdo con los ciclos de vida) y abandonada la juventud (Rodriguez, 2019). Pero lo interesante de la reflexión de Christine es que lo que aparece en los distintos hombres como capacidades separadas, en el rey sabio de la autora, por el contrario, aparece yuxtapuesto. Hete aquí que Carlos V representa la sumatoria de dichos conocimientos lo cual justifica la posesión de la perfecta sabiduría. Todas esas capacidades que el rey ya poseía y cultivaba durante su juventud, por pertenecer al linaje de los "elegidos" por gracia divina, son potenciadas a partir de su consagración, momento en el que el rey abandona la juventud y pasa a la etapa madura (Rodriguez, 2020). ${ }^{25}$ Carlos V aparece de este modo como la más perfecta potenciación del intelecto posible del que nos informa Dante en De monarchia:

Satis igitur declaratum est quod proprium opus humani generis totaliter accepti est actuare semper totam potentiam intellectus possibilis, per prius ad speculandum et secundario propter hoc ad operandum per suam extensionem (De mon., I.4: 86).

Pues hemos dicho suficientemente que la tarea propia del género humano, considerada en su totalidad, es la de actualizar sin cesar toda la potencia del intelecto posible, primeramente mediante la especulación y segundamente, como consecuencia, por medio del actuar, por extensión de dicha potencia (De mon., I.4).

Christine entiende de manera restrictiva -acotada al rey- lo que Dante entendía para el género humano. Aunque en clave restrictiva, Christine comparte con Dante que la búsqueda del conocimiento a través del intelecto contribuía a la máxima perfección

24 Ibid., I.13: 56: “or voit-il cler es choses troubles; or, lui ramentoit memoire l'experience des choses passées que il a veues, dont or à primes proprement au vray en scet jugier".

25 Ibid., I.13: 57: "mais n'est mie doubte que, se telz hommes, ainsi esleus, peuent vivre jusques en aage de meureté, que à cent doubles en eulx est creue la perfection de leur graces" [No hay duda de que, si estos hombres elegidos alcanzan la edad madura, en ellos se multiplica por cien la perfección de sus virtudes]. 
del alma. ${ }^{26}$ De ahí, que "la gloria y la felicidad de poseer un sutil y buen entendimiento sobrepasa a cualquier otra alegría" (Livre desfais, I.13). ${ }^{27}$ ¿Pero de que se trata esta actualización del intelecto del rey? Así como Christine interpreta de manera restrictiva el pasaje de la metafísica (sobre la posibilidad de desarrollar el saber), no es de extrañar que traslade dicha concepción al intelecto. Lo interesante resulta en observar, cómo la escritora asimila el intelecto perfecto al rey. En este sentido, si el intelecto aparece como el soberano bien, este es poseído en toda su plenitud por el monarca en una suerte de monopolio regio:

Tout ainsi que le bien d'entendement est le souverain des biens, car à lui tous les autres obeissent, par quoy naturelement les hommes sages soient seigneurs des autres, et ceulz qui deffaillent d'engin soient naturelement sers, car meismement ainsi nous le veons que naturelement le corps sert et l'ame seigneurist, comme nous veons les operacions du corps obeir aux afffections, lesquelles sont vertus de l'ame; ainsi comme raison seigneurist sensualité, et ainsi comme toutes les ars et science se convienent à une souveraine raine, laquelle a nom sapience, ainsi est il des hommes; comme à l'un affiere estre Roy duquel l'estat soit souverain sur tous autres (Livre desfais, III.63: 292).

El don del intelecto es el soberano bien, dado que todas las otras facultades le están sometidas; por esto, es natural que los hombres sabios gobiernen a los otros; inversamente, es natural que aquellos que son débiles de intelecto sean siervos; ya que también observamos naturalmente que el cuerpo obedece y el alma comanda, así como vemos los movimientos del cuerpo responder a las emociones, las cuales son atributos del alma, todo así como la razón domina a los sentidos. Del mismo modo que todos los artes y las ciencias son regidas por una ciencia soberana que llamamos sabiduría, sucede lo mismo con los hombres, dado que conviene que entre todos ellos haya un rey, cuyo rol sea ser soberano de todos los demás (Livre des fais, III.63).

Christine va a inferir del perfecto intelecto del monarca la teoría del poder (el gobierno de uno sobre otros). En este sentido, en tanto el rey es portador del soberano intelecto que alcanza la ciencia suprema, es por extensión portador del soberano bien de la comunidad política. ¿Acaso el entendimiento no es la virtud que permite la máxima comprensión de la naturaleza divina, el alcance de la "perfecta sabiduría"? Esta idea es plasmada en la figura del rey arquero que, aunque tomada de Egidio Romano, adquiere en Christine un significado por completo distinto.

La explicación de las causas conduce inevitablemente a la posición de supremacía que ofrece la ciencia arquitectónica (la ciencia principal) que tanto Christine como Tomás de Aquino y Nicolás Oresme definen como la ciencia del príncipe (política). Christine extrae del De regimine la figura del rey-arquero, la cual le permite establecer en el registro de las causalidades la superioridad del rey, representado por la figura del arquero, sobre el pueblo, identificado con la flecha. ${ }^{28}$ Así mientras el rey ve el blanco, conociendo los medios para alcanzarlo, el pueblo no es más que la flecha ciega ante el fin (cf. Livre des fais, III.63: 292). La ciencia del príncipe es

26 Dante, Il Convito, I.1: 1-2: "Siccome dice il Filosofo nel principio della prima Filosofia, tutti gli uomini naturalmente disiderano di sapere. La ragione di che puote essere, che ciascuna cosa da provvidenzia di propria natura impinta è inclinabile alla sua perfezione; onde, acciocchè la scienza è l’ultima perfezione della nostra anima, nella quale sta la nostra ultima felicità tutti naturalmente al suo desiderio siamo suggetti" [Como dice el filósofo al principio de la primera filosofía, todos los hombres, por naturaleza, desean saber. La razón de lo cual puede ser el que toda cosa impulsada por providencia de su propia naturaleza, se inclina a su perfección; de aquí que, pues la ciencia es la última perfección de nuestra alma, y en ella reside nuestra última felicidad, todos, por naturaleza, a desearla estamos sujetos].

27 Christine de Pizan, Livre des fais, I.13: 57: "la gloire et joye de soubtil et bon entendement precelle toutes autres leesces". 28 Véase al respecto Iogna-Prat y Rodriguez, 2017; Senellart 1995. 
precisamente aquella condensada en su intelecto que lo lleva a conocer las causas y por esto mismo acercarse a Dios. ${ }^{29}$ ¿Pero de que causas se trata?

Si Egidio Romano lo fundamenta en las leyes, Christine toma otro camino. Mientras el primero desarrolla la imagen de un soberano "casi Dios", en tanto "buen legislador" y donde "no hay más ley, porque él mismo es la ley" (Kantorowicz, 2012: 153-159), Christine se apoya en la paleta de ciencias a las cuales el soberano alcanza por su excelso intelecto. El conocimiento de las causas en Christine no está sustentado en un rey legislador (en todo caso conocedor únicamente del universal de la ley) sino en un rey científico construido a modo de arquitectura de ciencias. Si el rey se acerca a Dios es precisamente porque encarna aquel intelecto que le permite alcanzar todas las ciencias hasta llegar a la ciencia divina.

Por lo demás, si consideramos lo visto hasta aquí, hemos de integrar, entre estas ciencias, al arte y a las llamadas ciencias prácticas. Notemos, pues, la peculiaridad de la reflexión de Christine: la autora no solo hace del intelecto del rey el fundamento del poder sobre la sociedad civil (comunidad política), sino que su asimilación al intelecto divino sustenta la idea del vicariato regio:

je conclus que les choses plus sont prenables plus reçoivent de bien et plus sont generales et plus ressemblent à Dieu: doncques comme telle souveraineté, c'est assavoir majesté royal soit aucunement, en l'ordre des estas relative de Dieu, de la cause premiere de qui elle est vicaire aussi c'est juste chose qu'à l'exemple de lui, à quel similitude elle est instituée fin et chief de plusieurs, elle aussi se maintiegne et proporcionelment ses manieres ensuive: doncques, si comme Dieux influe sanz cesser ses largeces au monde, aussi et que les autres fins, soubz lui graduelement, selon leurs lois, habondent en vertus et influent aux autres, et plus l'ensuivent et plus sont perfaittes, semblablement en son equalité Roy leur doit ressembler; et doncques comme tel en France peust estre trouvé le bon roy Charles, à son vivant, dont la lueur des bienfais de ses vertus encore nous en redonde (Livre des fais, III.63: 293).

concluyo que la soberanía, es decir, la majestad real, es la más cercana a Dios en el orden de estados, dado que ella representa sobre la tierra la causa primera de la cual es vicario, asimismo es cosa justa que conforme al rol que le fue atribuido, ella adopte y siga las modalidades; dado que ella ha sido creada a imagen de Dios, para reinar sobre los otros y dirigirlos. Así Dios difunde continuamente las bondades en el mundo, y todo sistema organizado recibe de él un poder relativo a sus cualidades propias, que el transmite luego a otros: más son estos conforme al orden divino, más son ellos perfectos y es por esto que las cualidades del rey deben mostrarse semejantes a estos. Podemos decir, en efecto, que este fue el caso en Francia, durante la vida del buen rey Carlos, ya que los rayos de sus buenos hechos y de sus virtudes aún nos envuelven (Livre des fais, III.63).

En suma, el intelecto del rey asimilable al divino no solo constituye la teoría del poder laico (en sentido aristotélico: dominación de un individuo sobre el resto) sino de su vicariato divino. El análisis de Christine conduce inevitablemente a la divinización del saber científico por lo que el vicariato se presenta como un apéndice del estrecho vínculo existente entre el rey y el saber (ciencias, arte, etc.). Luego, a diferencia de Egidio Romano, la superioridad de un rey casi Dios no releva de la figura del rey

29 Christine de Pizan, Livre des fais, III.63: 292-293: "pour quoy, comme il appere le bien des choses soit en leur ordre et plus en fin qu'en l'ordre car fin met plus affett que les choses premisses, comme il appere jà Dieu estre fin de tout, de qui toutes ordres dependent, ne ne dependent de nulle, puis aussi que toutes choses sont ja mises en ordre, et en tel ordre a telle colliguance que les unes sont subgiettes aux aultres" [Es por esto que, constatando que la fuerza de las cosas reside en su organización y más aún en su fin que en la organización misma porque el fin importa más que el punto de partida , y que es evidente que Dios es el fin de todo, dado que toda cosa organizada depende de él, mientras que él no depende de ninguna; viendo entonces que todas las cosas están ordenadas jerárquicamente, y que en semejante orden algunas son sometidas a otras]. 
legislador sino de aquella del rey científico que encuentra en la figura del arquero, como del arquitecto, la asimilación con Dios: intelecto arquitecto del universo: "Dios sabiduría infinita, creador de todo orden" (Livre desfais, I.12). ${ }^{30}$

Dentro de la tradición "arquitectónica" de Aristóteles, Christine recupera la distinción artista/obrero, arquitecto/ejecutor, donde el primero, (a semejanza del arquero que divisa el fin) conoce mejor la finalidad de los trabajos que el segundo, simple trabajador en la realización del objetivo previamente concebido (cf. Livre desfais, III: 213-216; Iogna-Prat y Rodriguez, 2017). Desde este enfoque, el intelecto arquitecto del rey permite unificar ciencias especulativas y ciencias prácticas. No hay que olvidar que -tal como hemos visto con anterioridad- lo arquitectónico en Christine incumbe tanto al plano teórico como al práctico, desde el momento en que la ciencia arquitectónica (explicación de las causas) pertenece al príncipe (primer agente de la acción política).

Sin duda, la función de rey arquero/arquitecto/artista no puede más que ejercerse si no es con la ayuda de aquella virtud intelectual (razón) y moral (voluntad) contenidas en la prudencia. Precisamente la prudencia es la disposición del entendimiento que permite condensar y canalizar todos los saberes especulativos o prácticos en el terreno de las acciones humanas.

El cierre de toda esta reflexión ha de terminar, sin duda, en el capítulo 66 del Livre desfais -segundo y último capítulo dedicado a la prudencia- donde Christine expresa la esencia del rey prudente, aquella de ser ante todo un rey maestro. ¿Pero qué significa la cualidad de ser un rey maestro? En esencia, el maestro es aquel capaz de reproducir en actos todo aquello contenido en su intelecto; el mismo que teniendo un conocimiento acabado de las causas puede reproducirlas: "dice Aristóteles: 'El poder de enseñar es la marca del hombre sabio'; dado que es cuando una cosa puede producir otra cosa similar a si misma que es llamada perfecta en su funcionamiento" (Livre des fais, III.66). ${ }^{31}$ Del mismo modo en que el atributo del calor es aquel de poder calentar, la marca del sabio radica en el poder de enseñar y de producir el saber en el otro. A su vez, esto sería imposible sin la prudencia, "consejo de razón". ${ }^{32}$ Justamente, es esta la fuerza de la prudencia, aquella de ser una disposición arquitectónica capaz de reproducir en los hechos todo el contenido del intelecto (saber experimental, científico, etc.). Así, tal como alega Aristóteles, llamamos sabio a aquel que por la fuerza de su intelecto conoce las cosas difíciles que escapan al común de los mortales: "Luego, dice Aristóteles: 'Llamamos sabio a aquel que por la fuerza de su entendimiento conoce las cosas difíciles que escapan al común de los mortales" (ibid.). ${ }^{33}$ Notemos pues que Christine enfoca la atención no en el mero conocimiento experimental sino en las ciencias, dado que no llamamos sabio al que solo posee el conocimiento sensorial: "pero no decimos que el conocimiento que adquirimos por los sentidos releve de la ciencia" (ibid.). ${ }^{34}$ Así lo hemos visto para el caso de las ciencias del quadrivium.

El soberano bien, contenido en el intelecto, es perfectamente reproducible a escala de la política, de los hechos. Christine se encarga de dejar en claro que este rey versado en todo conocimiento (recorriendo la escalera de saberes hasta alcanzar la metafísica)

30 Ibid., I.12: 55: "Dieu, sapience infinie, acteur de toute fourme".

31 Ibid., III.66: 298: "dist Aristote: C'est le signe d'omme sage povoir enseignier; car, comme une chascune chose soit adonc perfecte en son operacion, quant faire peut autre semblable à elle”.

32 Ibid., III.66: 298: “car si comme c'est vertu de chaleur de povoir eschauffer autressi est ce signe de savoir de povoir enseigner, et science en un autre causer, lesquelles choses ne se pevent faire sanz cellui conseil de raison" [Si es lo propio de] calor el poder calentar, es entonces la marca del saber aquella de poder enseñar y de producir el saber en otro; y esto, no sabríamos hacerlo sin el consejo de razón].

33 Ibid., III.66: 298: “Après dit Aristote: Cellui nous disons cellui estre sage, qui est poissant de la vertu de son entendement à cognoistre choses qui soient difficiles et communement aux hommes non cogneues". 
es un hecho demostrable, precisamente, porque el soberano es ante todo un maestro. Siguiendo a la autora, llamamos entonces sabio a aquel que tiene más certeza de los conocimientos que el resto de los hombres y, por ende, puede explicar las causas, y así enseñar lo que sabe:

nous dison encore estre sage ycellui qui des choses qu'il scet a plus certaineté que les autres hommes et mieulz disant les causes; doncques cellui qui est sage doit savoir rendre cause de ce que on lui demande et par ce enseigner ce qu'il scet (Livre des fais, III.66: 298).

llamamos sabio a aquel que conoce más que los otros aquello que sabe, pudiendo explicar sus causas. El sabio, entonces, debe saber explicar las causas de todo aquello que se le demande, y así enseñar lo que sabe (Livre des fais, III.66).

La comprensión de las causas -propio de un gran intelecto- necesita de aquella virtud que, proviniendo del entendimiento, pueda trasladarse al campo de las acciones. Solo la prudencia, virtud intelectual y moral, está capacitada para cumplir con dicha función. Solo ella termina por otorgar una plenitud de sentido a la figura del rey arquitecto, puesto que permite cumplir con los dos registros contenidos en la metáfora arquitectónica: la concepción y la realización (IognaPrat, 2016: 173-220).

\subsection{La prudencia en obras}

La importancia de la realización del conocimiento resulta clave para la construcción de lo político en Christine de Pizan. La definición de prudencia como la virtud de lo contingente relacionada con la acción humana no tiene entonces que ver con el mero conocimiento empírico, sino con la plasmación en el campo de la política de todo lo contenido en el intelecto del rey. Son las mismas acciones las que aparecen demostrando en la práctica la perfecta sabiduría del rey, es decir, su enorme conocimiento en las distintas ciencias y artes al servicio de la política. Es la misma escritora la que se encarga de evidenciar la primacía de los hechos en una sabiduría regia definida, ante todo, por su ejercicio en el marco de la función real. En efecto, la prudencia del rey de Christine es primordialmente definible por las obras, hecho que se traduce por la primacía de lo práctico (concretamente a partir de hechos históricos contemporáneos) a lo largo de sus textos. En tanto todos los actos del rey aparecen conducidos por la prudencia, esta última adquiere un carácter totalizador que acapara la acción del rey a lo largo de la obra de la escritora (Rodriguez, 2016). La asimilación entre política y prudencia realizada por varios historiadores estudiosos del periodo (Chopin-Pagotto, 1999; Autrand, 2009) encuentra su justificación en el hecho de que el príncipe ha de actuar siempre prudentemente. ¿Pero qué significa actuar prudentemente según nuestra autora?

Resumiendo, actuar prudentemente no es otra cosa que emplear la cadena de medios disponibles para alcanzar el fin de la comunidad política. En lo fundamental, podemos decir que el fin de la comunidad política implica:

1. El porvenir en tanto "su gran prudencia lo lleva a reflexionar sobre las cosas venidera" (Livre des fais, III.6). ${ }^{35}$

2. El bien de la Corona de Francia y la utilitas publica: "por el bien de la Corona de Francia y de la utilidad común" (ibid.). ${ }^{36}$

3. El bien común en tanto "protector y defensor del bien común y del interés público, fue verdaderamente prudente" (ibid., III.7). ${ }^{37}$

35 Ibid., III.6: 205: "sa grant prudence lui amenistrast regart sur les choses à venir".

36 Ibid., III.6: 205: "pour le bien de la couronne de France et de la commune utilité".

37 Ibid., III.7: 207: "tres ameur et desireux du bien et proffit commun fust vray prudent". 
4. Una vida ordenada: "dado que las ciudades y los reinos fueron instituidos para que las comunidades humanas vivan en el orden" (ibid.). ${ }^{38}$

5. La salvaguarda del pueblo, puesto que el príncipe "debe ser prudente, teniendo previsión en toda cosa para la seguridad de su pueblo" (ibid., III.10). ${ }^{39}$

Para hacerlo el rey pone en acto su intelecto y es precisamente, esta, la definición de la prudencia. La prudencia es demostrada mediante la serie de hechos inteligentes acometidos por el rey; una suerte de relato ejemplar.

Al respecto, Christine no esconde su método de trabajo; por el contrario, nos lo explica. Este equivale a la primacía del ejercicio antes que la teorización: una sabiduría, antes que en dichos, en hechos. El método inductivo prima sobre el deductivo. En el caso de Christine, el oficio regio aparece como una cadena de acciones, todas regidas por la prudencia en vistas a la utilidad pública. Así, el monarca ha de "conducir sus obras por medio de la prudencia" (Livre des fais, I.4). ${ }^{40}$ Incluso en el libro III, dedicado a la episteme, la autora aclara en su prólogo: "procedamos, entonces, a la alabanza de tu sabiduría y de tus nobles acciones" (ibid., III. Prol.)..$^{41}$ En efecto, todas las acciones del rey traducen su prudencia y, por ende, en ellas se condensan los cinco fines aquí apuntados. La idea de prueba -de demostración- hace de los hechos la fuerza motriz del Livre des fais, tal como recalca la autora al final de su obra en el momento de recapitular los tres grandes temas trabajados (nobleza de corazón, caballería, sabiduría):

mais, sanz plus repliquer en eslonguement de matiere peut assez servir de soufficent preuve de utilité qui vient des. III. susdittes graces, la declaracion des fais et bonnes meurs du sage Roy, en qui nous les avons prouvées (Livre des fais, III.69: 305).

pero, nos será suficiente con recordar, para mostrar la utilidad inherente a estas tres virtudes, los hechos y buenas maneras del Rey sabio, de los cuales hemos demostrado su existencia (Livre des fais, III.69).

En síntesis, el Livre des fais aparece como una obra cuyo leitmotiv no es otro que el de probar, por medio de los hechos, la perfecta sabiduría del rey: "Reafirmamos, entonces, que el rey es un auténtico sabio, ya que lo comprobamos mediante las experiencias de su saber" (ibid., III.64). ${ }^{42}$ Una vez confirmada con pruebas fehacientes, esta perfecta sabiduría -encarnada en la figura del rey sabio- ha de volverse el modelo político de los futuros monarcas de Francia.

\section{Conclusión}

A lo largo de este artículo hemos intentado demostrar el vínculo entre episteme y política a partir de las virtudes del entendimiento y la prudencia. En cuanto al entendimiento, podemos decir que constituye la virtud que permite al rey equipararse a un maître universitario, en tanto la superioridad de su intelecto le permite alcanzar el vértice de la arquitectura de ciencias, la ciencia divina. Por su parte, la prudencia es aquella virtud intelectual como moral que permite volcar en el plano de lo contingente todos los saberes contenidos en el intelecto del rey (desde la ciencia meramente especulativa hasta los conocimientos más prácticos). Esta

38 Ibid., III.7: 209: "puisque citez et royaumes sont ordenez pour congregación humaine mener en vie ordennée".

39 Ibid., III.10: 212: "Sage doit estre prudent, pourveu de toutes choses à la sauveté de son peuple".

40 Ibid., I.4: 39: "conduire ses fais par prudence".

41 Ibid., III. Prol.: 197: “Soit doncques procedé à la louenge de sapience et de voz valeureuses euvres”.

42 Ibid., III.64: 294: "Encore derechief le povons conclurre sage, par ce que prouvé avons des experiences de son sçavoir”. 
operación es la que termina por convertir todas las ciencias y saberes en elementos constitutivos de la ciencia política, que surge asimismo gracias a la prudencia.

En síntesis, esta última aparece como aquella virtud que pone en ejercicio la perfecta sabiduría del rey a partir de las obras llevadas a cabo por el monarca a lo largo del Livre des fais y de los otros escritos políticos de la autora. Si avanzamos en la reflexión, el intelecto del rey aparece como la esencia, la causa primera del cuerpo de la política. No obstante, dicha sustancia no es nada si no va acompañada de la prudencia. Es justamente esta última virtud la que permite la realización de la sustancia primera mediante la reproducción (la generación de una sustancia igual a sí misma). En este sentido, la figura del rey prudente como rey maestro viene a completar la figura del rey arquitecto en el dominio de todas las ciencias. Concepción, realización y reproducción del saber en el marco del reino aparecen como los tres elementos constitutivos de la sabiduría perfecta encarnada en el monarca francés.

Finalmente, el tratamiento restrictivo -acotado a la persona regia- de las premisas del conocimiento humano de la Metafísica aristotélica permite hablar de la potencialización del intelecto en la figura del rey. Pero dicha potencialización se encuentra fundamentalmente inscrita en la función real. De hecho, la teoría de los "elegidos" viene a marcar, en parte, esta idea del intelecto consagrado a la actividad política. Desde esta perspectiva, este intelecto potenciado que opera en el marco del reino nos permite hablar de una suerte de realeza antropocéntrica en donde el intelecto del rey aparece como epicentro del cuerpo de la política. En este sentido, el intelecto del rey se presenta como el fundamento de la teoría de gobierno. Así, el saber científico al servicio del Estado, encarnado en el soberano, aparece como la justificación de la dominatio. Pero esto no acaba allí. Jefe supremo del cuerpo político, el intelecto regio también expresa la función del rey como vicario de Dios. En este sentido, podemos apreciar una suerte de trascendencia de la política que ha de pasar por la divinización de las ciencias y por consiguiente por la divinización del intelecto real, que vuelve al rey un símil de Dios, gran arquitecto del universo. Advirtamos como el rey científico se encuentra en la base tanto del imperium orbis terrarum como del imperium Christi. Ni legislación ni consagración eclesiástica se vuelven necesarias para el dominio de la ciudad terrestre y la ciudad celeste. En este sentido, el intelecto del rey permite prescindir tanto del legado romano como del eclesiástico despejando el camino para una verdadera realeza antropocéntrica. 


\section{Bibliografía}

\section{Fuentes}

\section{Ediciones y traducciones}

"Christine de Pizan (1986). Le Livre de la cité des dames. Ed. Hicks, E. y Moreau, T. París: Stock.

»Christine de Pizan (2001). Le Livre de l'advision Cristine. Ed. Reno, Ch. y Dulac, L. París: Honoré Champion.

"Christine de Pizan (2008). The Book of Peace (Livre de la paix). Ed. y trad. Green, K., Mews, C. y Pinder, J., Pensilvania: The Pennsylvania State University Press.

"Christine de Pizan (2009). Le livre des fais et bonnes meurs du sage roy Charles V. Ed. Desgrugillers, N. Clermont-Ferrand: Paleo.

»Dante Alighieri (1831). Il Convito. Ed. Fortunato Cavazzoni Pederzini Modonese, Módena: Tipografia Camerale.

"Dante Alighieri (1993). La monarchie. Trad. Gally, M. París: Belin.

"Nicole Oresme (1940). Le Livre de éthiques d'Aristote. Ed. Menut, A. D. Nueva York: Stechert.

" Tomás de Aquino (1947). St. Thomas Aquinas: Summa theologica. Ed. Fathers of the English Dominican Province, Cincinnati: Benziger Bros.

\section{Bibliografía complementaria}

" Autrand, F. (2009). Christine de Pizan: Une femme en politique. París: Fayard.

"Chopin-Pagotto, M. (1999). "La prudence dans les Miroirs des princes", Chroniques italiennes 60, 87-98.

»Daguet, F. (2017). Du politique chez Thomas d'Aquin. París: Vrin.

"De Libera, A. (1998). La Philosophie médiévale. París: Presses Universitaires de France.

"Delogu, D. (2008). “Christine de Pizan lectrice de Gilles de Rome”, Cahiers de recherches médiévales 16, 213-224. URL: http:// journals.openedition.org/crm/10852.

»Green, K. (2008), "Introduction”. En: The Book of Peace by Christine de Pizan. Pensilvania: The Pennsylvania State University Press, 1-31.

»Hibbs, T. S. (2001). Virtue's Splendor: Wisdom, Prudence, and the Human Good. Nueva York: Fordham University Press.

" logna-Prat, D. (2016). Cité de Dieu, Cité des hommes. L'Église et l'architecture de la société. 1200-1500. París: Presses Universitaires de France.

» logna-Prat, D. y Rodriguez, J. (2017). "Política y ciencia de la arquitectura en la Francia de finales de la Edad Media. Un estudio de caso: Christine de Pizan". En: Estudios en Historia Moderna desde una visión atlántica: Libro homenaje a la trayectoria de la profesora María Inés Carzolio, t. II. La Plata: Editorial de la Facultad de Humanidades y Ciencias de la Educación, 233-248. 
"Kantorowicz, E. (2012). Los dos cuerpos del rey. Un estudio de teología política medieval. Madrid: Akal.

»Le Ninan, C. (2013). Le Sage Roi et la clergesse. L'Écriture politique dans l'œuvre de Christine de Pizan. París: Honoré Champion.

" Lusignan, S. (1999). "Vérité garde le roy". La construction d'une identité universitaire en France (XIIle-XVe siècle). París: Publications de la Sorbonne.

"Quillet, J. (1984). "Présence d'Aristote dans la philosophie médiéval", Revue De Philosophie Ancienne 2.2, 93-102. URL : www.jstor.org/stable/24353770.

"Rodriguez, J. (2015). "Entorno a una controversia: Christine de Pizan, autora del Livre de fais et bonnes meurs du sage roy Charles V', Actas VII Jornadas de Estudios Clásicos y Medievales "Diálogos Culturales". URL: http://sedici.unlp.edu.ar/handle/10915/55386.

"Rodriguez, J. (2016). "La phronesis real en la teoría política de Christine de Pizan", Cuadernos Medievales 21, 121-135. URL: http://fh.mdp.edu.ar/revistas/index.php/cm/article/view/1683/1887.

" Rodriguez, J. (2019). "El lenguaje político de la juventud en el Livre des fais et bonnes meurs du sage roy Charles V', Exlibris 8, 73-89. URL: http://revistas.filo.uba.ar/index.php/exlibris/article/view/3284.

"Rodriguez, J. (2020). "Una nueva especie de consagración real. La conversión intelectual del rey en el Livre des fais et bonnes meurs du sage roy Charles V', Anales de Historia Antigua, Medieval y Moderna 54. 1, 31-48. URL: $\quad$ http://revistascientificas.filo.uba.ar/index.php/analesHAMM/article/ view/7572/7415.

"Senellart, M. (1995). Les arts de gouverner, du regimen médiéval au concept de gouvernement. París: Seuil.

»Verger, J. (1997). Les gens de savoir dans l'Europe de la fin du Moyen Âge. París: Presses Universitaires de France. 